\title{
Enhancing English Morphological Acquisition for Early Childhood Learning through an Online Game
}

\author{
Ima Widyastuti, Adria Vitalya Gemilang, Dita Surwanti, Isti'anatul Hikmah, Victa Sari \\ Dwi Kurniati, Adhikusuma \\ \{widyastuti_ima@yahoo.com¹, vitalyaisme@gmail.com², coraldita@gmail.com³, \\ ihikmah99@gmail.com ${ }^{4}$, victasari@gmail.com ${ }^{5}$, adhioffice@gmail.com $\left.{ }^{6}\right\}$
}

English Department, University of SarjanawiyataTamansiswa, Yogyakarta, Indonesia ${ }^{1,2,3,4,5,6}$

\begin{abstract}
Playing an online game promotes learning for the very early bilingual childhoods who are learning English as their third language. The participant of this study learn new English words which are the basic component of the English morphological developmental acquisition proposed by Processability Theory (PT). After two months playing Happy Aquarium with the guidance of an adult, the participant of this research has reached the Stage One of PT. In his age of 5 year old, the participant is still able to recall all vocabulary inventory after his absence in playing the game. The discussion of the second language acquisition (SLA) is focused on the learning strategy and age. The findings of this study will be used as a part of material development in English preschools in Indonesia.
\end{abstract}

Keywords: SLA; PT; Age.

\section{Introduction}

Traditionally, games are run through physical interaction. However, nowadays, online games are spread fast and introduced across ages. Compared to the traditional games, online games elicit more different typed of interactions and learning. Even though some researchers viewed that technology including online games promoted negative effects for childhood [1], some online games for early childhood offer positive learning. As children on the age of two have not had literacy competent at all, the positive guidance and parenting will positively influence children's life adjustment [2]. Some researchers have been worked in online games with the adult or children players in relation to the literacy skills and knowledge. However, little researchers focus on the language production on early childhoods who are learning English as their third language.

The present study attempts to address the gap by providing a quantitative data gathered from an Indonesian boy who has been playing Happy Aquarium game on Facebook with the adult's companion. He has been introduced this game in order to enrich his English input as his third language. The discussion of the study is limited on the help of the game in enhancing English morphological acquisition for early childhood. The purpose of this study is to see the number of English vocabulary gained after two months playing Happy Aquarium game. Besides, this is also to see the participant's vocabulary inventory after two year without English input related to the Happy Aquarium game. These two purposes will be used as the 
preliminary study in developing material in English Preschool in Indonesia which adopts the English morphological acquisition based on the Processability Theory [3].

Based on this theory, the L2 learners can only produce the L2 structures which they have known in sequences. In the Processability Hierarchy, there are five stages which cannot be skipped. Stage One is for word or lemma access in which the L2 learners are only able to produce single words without any grammatical information. Stage Two is for Categorical Procedure where the L2 learners start to order words into sentences canonically. Stage Three is for Phrasal Procedure. On this stage, the L2 learners can combine both head and modifiers on the phrasal structures. Stage Four is called S-procedure where the L2 learners are able to produce sentences which require agreements between the subjects and verbs. The last stage is Stage Five named S'-procedure where the L2 learners can use sentences with subordinateclauses.

The recent study only focuses on the first stage of the Processability Hierarchy. Even though this stage does not offer any processing procedure as it is non-analysed material, this stage is important for the new learners. This is the bedrock of the L2 learners before moving on the next stages of the L2 development. Before reaching the Stage One, the L2 learners are introduced a language system which combines between form and meaning called a sign [4]. In this study, for instance, the words "fish" brings a language system referring to signs such as water animal, moving with fins, and breathing using gills.

Happy Aquarium is basically a two-dimensional game. This fish tank game has all the features of a real tank such as fish, lighting, wallpaper, fish food, cleaning stuff, and tank's decorations. This game is released by CrowdStar in 2005 [5]. Even though this is categorized as a social game, Happy Aquarium also offers multiple choices for different style of individual or social game players. The players can play individually such as cleaning their own fish tanks, feeding fish, mating fish, hunting treasure, opening chest treasure, expanding and decorating tanks and training fish. They can also play with friends such as helping orphans and releasing trapped fish or other marine creatures. To support both individual and social activities in-game, Happy Aquarium is completed with simple icons navigations on the top and bottom of the tank.

\section{Method}

Happy Aquarium was chosen by the parents as their son loved fish. During the process of learning using Happy Aquarium, his parents tried to speak English even though their son's first and second languages are Javanese and Bahasa respectively. The participant did not get any English input except when he played Happy Aquarium. The research applied a case study approach. The data was gathered from the participant observation.

This longitudinal study invited an Indonesian boy. The first and the second data collection were taken when he was 2 years old and 5 years old respectively. Between the first and the second data collection, the participant did not play Happy Aquarium again but he sometimes recalled English words he knew whenever his parents asked. In the first observation, the participant was accompanied by his mother to play the game. However, in the second observation, the participant played alone without his parent companion due to his ability in operating computer. In doing some activities in the game, the participant was asked to identify and pointed marine creatures' names as well as their names shown on the Happy Aquarium. 
As the participant has known some words in Javanese and Indonesian, he sometimes did not name things in English.

Between the first and the second data collection, the participant never plays Happy Aquarium due to bad internet connection. However, his parent sometimes asked him the English words of things provided in Happy Aquarium. Besides, the participant also got input from his preschool teachers. The observation was video-recorded and transcribed. All English words produced were simply counted and grouped into two; correct and incorrect English words. The acquisition criterion applied is using an emergence criterion which refers to the first production of the L2 [3] and was set at four tokens in contexts [6]. Tokens are all repetitions made by the learners in contexts [7], for example, the participant repeated the word "coin" three times so it was counted three tokens but was only counted as one type of obligatory context. Tokens are chosen to see the real presentation of the morpheme productions [7].

\section{Results And Discussion}

\subsection{The first data collection}

From the observation on the 2.3-year-old-Indonesian boy, there were 8 in-game individual activities played by the participant with his parent's companion: opening treasure chests, cleaning tanks, feeding fish, frog adoption, shopping in-game store, mating fish, fish training and hunting treasure. In opening treasure chests, cleaning tanks, feeding fish, and frog adoption, the participant did himself with very limited guidance from the adult.

The table 1 shows the in-game activities in Happy Aquarium, and words which the participant was able to utter spontaneously when he saw the images, when the parent clicked the objects, or when the researcher pointed the objects.

Table 1. Language production during playing in-game activities

\begin{tabular}{ll}
\hline \multicolumn{1}{c}{ In-game activities } & \multicolumn{1}{c}{ Possible single words acquired } \\
\hline opening treasure chests & chest, open, bubble, close, coins, shell, egg \\
cleaning tanks & dirty, brush, clean \\
feeding fish & food, bottle, ikan, biscuit \\
frog adoption & frog, green, pink, eyes, baby frog \\
shopping in-game store & eagle ray, eel, porcupine, dolphin, shark, \\
& mermaid, fin, house, rock, crab, prawn, \\
& starfish, jellyfish, squid, boat, green, red, \\
& pink, blue, purple, yellow, black, grey, \\
& orange, brown, nemo, small, big \\
mating fish & egg, hatch, bubble \\
training fish & coin, umbrella, \\
hunting treasure & coin, treasure \\
\hline
\end{tabular}

The main tank has a treasure chest which can be opened once a day by clicking the image. One particular treasure such as coins, shell, egg, or other props will be gained. In the observation, when the participant clicked his and his friends' tank chests, the participant spontaneously produced seven correct English words: chest, open, bubble, close, coins, shell, and egg. Cleaning tanks activity, basically is used to add points for increasing the game level. The participant clicked the brush image many times until the tank got clean. In the observation, the participant could only say "brush" many times, "dirty" and "clean". Similarly, 
in feeding fish activity, the participant clicked the food bottle icon and said "ikan" many times. The participant knew that "ikan" refers to "fish", however, the participant seemed to play with the word "ikan" and refused to pronounce it into English. Every time the participant said "ikan", he smiled as if he challenged his mother with his languages. From the mother explanation after the observation, it was revealed that the word "fish" was the participant's first English word introduced due to his interest in this creature. However, the participant frequently avoided to say "fish" every time he saw that object. In this case, the participant showed an example of gaining his identity through language [8].

As "ikan" is not an English word, this was not counted. The participant, however, was able to produces three English words in feeding fish activity; food, bottle, and biscuit. Different from other in-game activities in Happy Aquarium, frog adoption activity needs the players to click the frog icon everyday during 14 days. If the players miss one day, they have to start from the beginning without losing of the frog. The participant of the study produced four English single words; frog, eyes, green and pink; and one noun phrase, i.e. baby frog. In shopping in-game store, the participant was able to produce twenty seven correct English words from twenty eight instances by naming some marine creatures and their colors shown in the game-store such as eagle ray, eel, porcupine, dolphin, shark, mermaid, fin, house, rock, crab, prawn, starfish, jellyfish, squid, boat, green, red, pink, blue, purple, yellow, black, grey, orange, brown, small, and big. The word "nemo" was not counted as this is the name of a clown fish shown in the movie entitled Finding Nemo. The number of words produced by the participant from this shopping in-game activity is the highest than other activities in Happy Aquarium. This is because the game store offers a huge number of colorful marine objects and aquarium properties which attract the participant attention. In other words, the participant got many inputs from this game store. Besides buying fish or properties from the game store, the player can mate their fish to get new fish. By clicking the chosen fish, a mini box for mating will appear. The participant only produced three words: bubble, egg and hatch.

In Happy Aquarium, there are two mini game provided; training fish and hunting treasure. Fish can be trained to gain extra coins and food. Once a chose fish is clicked for training, it will be move to a mini game. The simple icons such as number of lives, food and coins are located on the top of the mini game screen. To reach the finish line safely, the fish has to avoid poison bottles and click some hazardous obstacles such bear's claws and umbrellas. In the observation, the participant did not do many clicking so that the parent did. However, the participant could produce two English words; "coin" and "umbrella." Besides training fish, another mini-game on Happy Aquarium is hunting treasure. Similarly to the training fish minigame, after clicking the icon hunt treasure and choose a fish, a mini game will appear and the player has to guide the chosen fish to go around coral for a treasure chest and coins in 45 seconds. What is inside the treasure chest will be revealed when the chosen fish is returned to the tank, but mostly it is jewelry such as diamond, ruby and emerald. The participant of the present study looked very enthusiastic by producing two English words; "coin" and "treasure," and yielding some unclear words of making a story. This is in line to what [9] found that children tend to narrate what they are doing such as moving objects and characters around on the screen during the game. Even though the participant in the present study has not been able to use move the fish in training fish and hunting treasure, he narrated what he saw on the screen.

Among the eight in-game activities observed, the participant produced 46 English words correctly from 55 words produced. This means that the participant of this study had produced more than four tokens in contexts set for this study. This also means that the participant has reached Stage One of PT English morphological development. The huge number of tokens the 
participant produced also shows that technology is intrinsically motivating so that simultaneous acquisition of concepts, as well as of the English language can be occurred [10]. In other words, the participant of this study learnt the English as his L2 in external L2 setting. In this kind of learning setting, the language learnt is not the language used in the society dominantly [11]. English is not used in his daily communication with his parents and friends. During two months, he got his first English input from game with the guidance of his parents. From the observation, the participant was able to produce English lemmas even though he still communicated with his parents and friends in Bahasa and Javanese. He was able to switch his language when he played the game. This means the participant is able to accept more than one language in his very early age.

\subsection{The second data collection}

When the participant was 5 years old, he was invited to play Happy Aquarium. Amazingly, without any effort, he was able to recall all words he produced when he was 2 years old, except the word "ikan". He mentioned fish, not "ikan" anymore. He produced more words and expressions during the game. As he has known numbers, he often counted properties on this game. However, he always missed the suffix $-\mathrm{s}$ for showing plural nouns, for example, two frog, three sea ell, two prawn, and two crab. It is understandable as in Javanese and Indonesian, there is no plural suffix $-\mathrm{s}$ addition rule. The bulk words and expressions the participant produced are due to stories he made. He told about the fact of shark, for example, when he saw the image of shark on the in game shop. He also retold a cartoon movie entitled Finding Nemo when he saw an Eagle Ray, a fish species. This supports the idea that children languages develop from their experiences as a part of input. The participant of this research was able to expand his third language by connecting his experience and what he saw in Happy Aquarium. Besides, he sometimes asked the English words he has not known yet, then, he repeated several times after his parent mentioned the English words he asked. [12] mentioned that children become active to learn if they are actively questioning.

From the first and the second data, it can be seen that the participant was able to remember all English words introduced. Though the participant had not been able to read yet, he could recognize the images shown on the Happy Aquarium game and mention the images English words which were introduced by his mother. Thus, the participant was able to understand the language signs and codes. For instance, on the first data collection, when the mother said that the aquarium tank was dirty in Indonesian, the participant directly pointed the brush image which was commonly used for cleaning the tank. This led to the prediction that the participant would be able to develop the English vocabulary inventory afterward.

Though, of course, his language development will depend on the input from his surrounds [13]. The data gained on the second observation, then, proved the prediction. His English grew rapidly through story telling he made during playing the game. This means that new language introduced in early childhood can be stored and recalled. This also proved that between the ages of 2 and 6, children can acquire language fast and effortlessly [14] even though that language is not their first language.

\section{Conclusion}

By applying the emergence criterion to the results, the participant of this study reached Stage One of PT English morphological acquisition after two months getting input from 
Happy Aquarium game with guidance of his parents. The participant was also able to store and recall English word inventory introduced in his early age even though he got limited input of external language setting.

\section{Recommendations}

In the future research, doing other longitudinal study would be interesting to see the higher English developmental acquisition with the help of other games or applications. Another research on preschool students' second language acquisition would also be more challenging as nowadays, technological devices such as android, iPad, and tablet have been become familiar to children at home and would be a prominent choice among teachers and parents [15]. In the school, however, the teacher companion during the use of technology is still in the high priority so that the children gain save exploration and experience [16]. Teachers should take cognitive, technical and affective scaffolding consideration when the children connect with technology [17]. Besides, teachers may combine the learning activities both online/computer games and traditional physical games. In gardening activities, for example, children will have much more physical movement than only sit in front of the computers. Teachers provide some inputs while accompany children planting, watering or even only observing garden, field, or river.

\section{References}

[1] C. Cordes and E. Miller, Fool's Gold: A Critical Look at Computers in Childhood. College Park, MD: Alliance for Childhood, 2000.

[2] S. C. Kong and K. M. Li, "Collaboration between school and parents to foster information literacy: Learning in the information society," Comput. Educ., vol. 52(2), pp. 275-282, 2009.

[3] M. Pienemann, Language processing and second language development: Processability Theory. amsterdam: John Benjamins., 1998.

[4] G. Kress, Before writing: Rethinking the paths to literacy. London: Routledge, 1997.

[5] CrowdStar, "CrowdStar Enters Into Five-Year Strategic Relationship With Facebook: Facebook Credits to Become Exclusive Global Virtual Currency for All CrowdStar Games," 2010. [Online]. Available: http://www.marketwire.com/press-release/CrowdStar-Enters-Into-Five-Year-StrategicRelationship-With-Facebook-1283401.htm. . [Accessed: 12-Oct-2010].

[6] Y. Zhang, "A note on the accuracy criterion and the emergence criterion," Chinese Teach. World, vol. 65, pp. 52-60, 2003.

[7] G. Pallotti, "An operational definition of the emergence criterion," Appl. Linguist., vol. 28, pp. 361-382, 2007.

[8] J. Bernstein, B., \& Solomon, "Pedagogy, identity and the construction of a theory of symbolic control Basil Bernstein questioned by Joseph Solomon," Br. J. Sociol. Educ., vol. 20 (2), pp. 265 $279,1999$.

[9] S. Bredekamp and T. Rosegrant, Reaching potentials: Appropriate curriculum and assessment for young children. Washington, D.C: National Association for the Education of Young Children, 1992.

[10] C. E. García, "Using animation software to assist second language learners in science learning," University of Colorado, 1999.

[11] J. Siegel, Social context. In C. Doughty \& M. Long (Eds.), The handbook of second language acquisition. Oxford: Blackwell, 2003.

[12] E. Winner, M. McCarthy, S. Kleinman, and G. H, In D. Wolfe (Ed.), Early symbolization (New

Directions for Child Development, No. 3). San Francisco: Jossey-Bass, 1979. 
[13] K. Topping, R. Dekhinet, and S. Zeedyk, "Parent-infant interaction and children's language development," Educ. Psychol., vol. 33, pp. 391-426, 2013.

[14] M. Cole and S. Cole, The development of children. New York: Scientific American Books, 1993. [15] A. L. Gutnick, M. Robb, L. Takeuchi, and J. Kotler, Always Connected: The New Digital Media Habits of Young Children. New York: The Joan Ganz Cooney Center at Sesame Workshop, 2011.

[16] K. J, "Should computers be used in preschools?," 2012. [Online]. Available: www.parentmap. [Accessed: 06-Jun-2012].

[17] N. Yelland and J. Masters, "Rethinking Scaffolding in the InformationAge," Comput. Educ., vol. 48 (3), pp. 362-82, 2007. 